\title{
Screening programs overlook transgender people
}

$\mathrm{S}$ hoshana had her first mammogram in her early $60 \mathrm{~s}$ - more than a decade after most women start regular screening for breast cancer.

"I'd been seeing my doctor for hormones for four years, but the idea or need for me to do a mammogram was never raised, so I asked him if I needed one," she says. The doctor was stumped. "I was his first older transgender patient."

Now, Shoshana is screened every two years. "I'm one of the lucky. I've always been very proactive about my health, but there are times when you don't know the questions to ask," she says.

According to the Canadian Cancer Society (CCS), transgender people are less likely to undergo regular screening or get tested when they have symptoms that may indicate cancer.

Some transgender patients may not be aware of their risk for cancer in body parts they dislike or have altered, says Susan Flynn, manager of the society's Screening Saves Lives program. For example, transgender men may feel uncomfortable having their breasts examined, or assume that having a cosmetic mastectomy will protect them from breast cancer. Transgender women like Shoshana may not appreciate that new breasts and neo-vaginas may also need to be checked for abnormalities.

For others, "cancer and screening are not high on the priority list when they're dealing with other health issues related to surgery and hormones," says Flynn.

The biggest barrier, though, is pervasive discrimination and ignorance in the health system.

A 2010 survey of some 7000 transgender Americans revealed that 28\% postpone necessary care when sick or injured due to discrimination. Half of the participants reported having to teach their providers about transgender care, while $19 \%$ reported being refused care due to their transgender status.

Sex-segregated systems, such as hospital wards and women's clinics often force patients to choose between accessing services according to their birth sex and forgoing care entirely.

Health documentation and physician

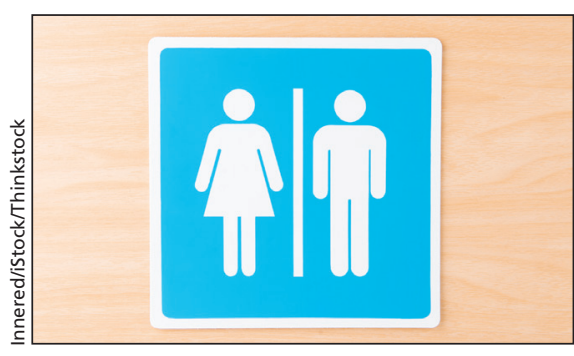

Transgender patients face multiple hurdles to cancer screening, not least ignorance and discrimination from health workers, says the Canadian Cancer Society.

fee schedules are similarly blind to the fact that a patient's gender and anatomy may not match or remain fixed over life. The upshot: patients with male anatomy who have changed their sex to female under provincial health insurance may not receive coverage for prostate exams.

"The courage it takes for a transgender person to walk into a doctor's office is enormous," particularly for an intimate examination, says Shoshana. She cites personal experiences of being turned away from clinics and health workers refusing to use her chosen name. Now, Shoshana calls ahead to prepare hospital and clinic staff for her visits.

According to Flynn, part of the problem is a lack of policies that accommodate transgender bodies or awareness that such policies are needed.

The cancer society's Get Screened website now compiles transgenderspecific screening information for patients and physicians, but little is known about the community's unique risks for cancer, particularly when it comes to the long-term effects of medical transition through hormones or surgery.

A CCS literature review revealed only a handful of studies done on small samples and a dearth of clear guidelines for physicians, says Flynn.

CCS will provide an online course for physicians on providing transgender health care in coming months. The accredited course will cover screening and creating an inclusive practice for transgender patients. - Lauren Vogel, CMAJ

CMAJ 2014. DOI:10.1503/cmaj.109-4839 